\title{
ALCHEMI Studies of Spinel Oxides for SOFC Interconnect Alloy Coatings
}

\author{
Louis V. Gambino ${ }^{1}$, Neal J. Magdefrau ${ }^{2}$, and Mark Aindow ${ }^{1}$ \\ 1. Department of Materials Science and Engineering, and Institute of Materials Science, University of \\ Connecticut, Storrs, CT 06269, USA \\ 2. United Technologies Research Center, East Hartford, CT 06108, USA
}

Manganese cobalt oxide (MCO) spinels are used as coatings on metallic interconnects for solid oxide fuel cells (SOFCs) because they inhibit outward diffusion of $\mathrm{Cr}$ while exhibiting polaronic conductivity that gives acceptable contact resistances [1]. We have recently shown that MCO-coated Crofer 22 APU develops a complex reaction layer (RL) at the alloy/coating interface, and we have proposed that the mechanism of formation is related to the site occupancies of $\mathrm{Cr}, \mathrm{Fe}$ and/or $\mathrm{Ni}$ ions diffusing into the MCO from the alloy [2,3].

Here we report a study of these effects in which we firstly consider a series of model ceramic MCO spinels with Cr-, Fe- and Ni- substituted compositions. Powders of the appropriate compositions were produced by glycine nitrate combustion synthesis, and these powders were consolidated into ceramic pellets by pressing and pressure-less sintering. Conventional ceramic TEM samples produced by dimpling and Ar ion milling were analyzed using planar ALCHEMI on grains oriented close to the 400 systematic row. The data were plotted using the ordering tie line (OTL) approach introduced by Hou et al. [4]. In each case, the OTLs extrapolated to identify the sub-lattice compositions for the most highly ordered state consistent with the sense of order measured experimentally. These data were then compared with measurements from the RL in MCO-coated Crofer 22 APU coupons that had been oxidized in air at $800^{\circ} \mathrm{C}$ for $1000 \mathrm{~h}$. FIB-cut cross sections through the coating/alloy interfaces were analyzed and ALCHEMI data were obtained at various points through the RL thickness corresponding to different levels of cation substitution into the MCO structure.

Examples of the OTLs for ALCHEMI data obtained from Cr-substituted ceramic MCO samples are shown in Figure 1. For the samples with low and intermediate $\mathrm{Cr}$ contents the site occupancies show the expected trends with $\mathrm{Co}$ on the tetrahedral A sites and $\mathrm{Mn}$ and $\mathrm{Cr}$ on the octahedral $\mathrm{B}$ sites. For the high $\mathrm{Cr}$ sample, however, the $\mathrm{Cr}$ displaces some of the $\mathrm{Mn}$ onto the A sites so that at this composition the proportions of $\mathrm{Mn}$ are the same on both sites.

The microstructure of the interface in the MCO-coated Crofer 22 APU after $1000 \mathrm{~h}$ oxidation as shown in Fig 2(a) contains: the alloy, a 1-2 $\mu \mathrm{m}$ thick fine-grained chromia layer, a $\mathrm{RL} \approx 5 \mu \mathrm{m}$ in thickness, and the unaffected MCO coating. There is a compositional gradient within the RL and Fig. 2(b) shows the regions of low (10\%), medium (28\%) and high (44\%) Cr content within the RL. The corresponding OTLs are shown in Fig. 3. For the regions of medium and high $\mathrm{Cr}$ content within the RL, the sense of the ordering is broadly consistent with that expected on the basis of the data from the Crsubstituted ceramic samples. For the low $\mathrm{Cr}$ sample, however, both the sense and extent of ordering are very different. This can be explained on the basis of the effects of other substitutional cations (mainly $\mathrm{Fe}$ ) in the RL, and the fact that the MCO coatings are undergoing a structural transformation under the influence of a diffusive flux whereas the ceramic samples adopt an equilibrated cation distribution.

\section{References}

[1] Z. Yang, G. Xia, X. Li, J. Stevenson: Int. J. Hydrogen Energy, 32 (2007) p. 3648.

[2] N.J. Magdefrau, L. Chen, E.Y. Sun, J. Yamanis, M. Aindow, J. Power Sources 227 (2013) p. 318.

[3] L.V. Gambino, N.J. Magdefrau, M. Aindow. Mater. High Temp. 32 (2015) p.142.

[4] D.H. Hou, I.P. Jones, H.L. Fraser. Philos. Mag. A 74 (1996), p. 741. 

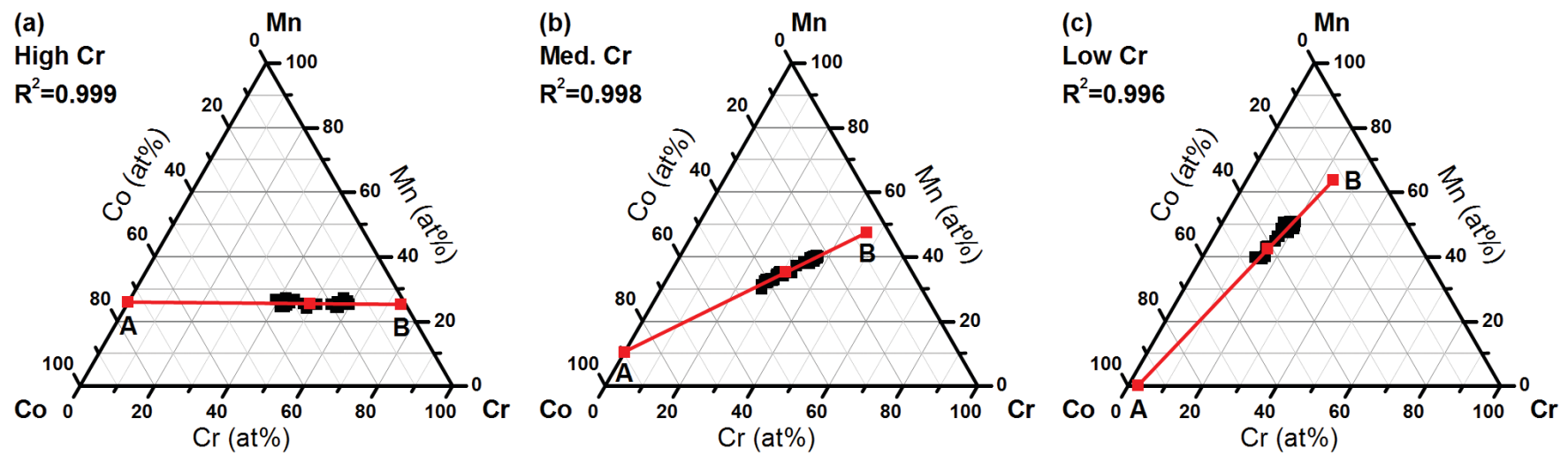

Figure 1: OTL plots of ALCHEMI data obtained from ceramic $\mathrm{Mn}_{1.5-\mathrm{x}} \mathrm{Co}_{1.5-\mathrm{x}} \mathrm{Cr}_{2 \mathrm{x}} \mathrm{O}_{4}$ spinels with $\mathrm{x}=0.75$ (High $\mathrm{Cr}$ ), 0.5 (Med Cr) and 0.25 (Low $\mathrm{Cr}$ ). The OTL endpoints mark to compositions for the tetrahedral (A) and octahedral (B) sites in the most highly ordered $\mathrm{AB}_{2} \mathrm{O}_{4}$ normal spinel structure.
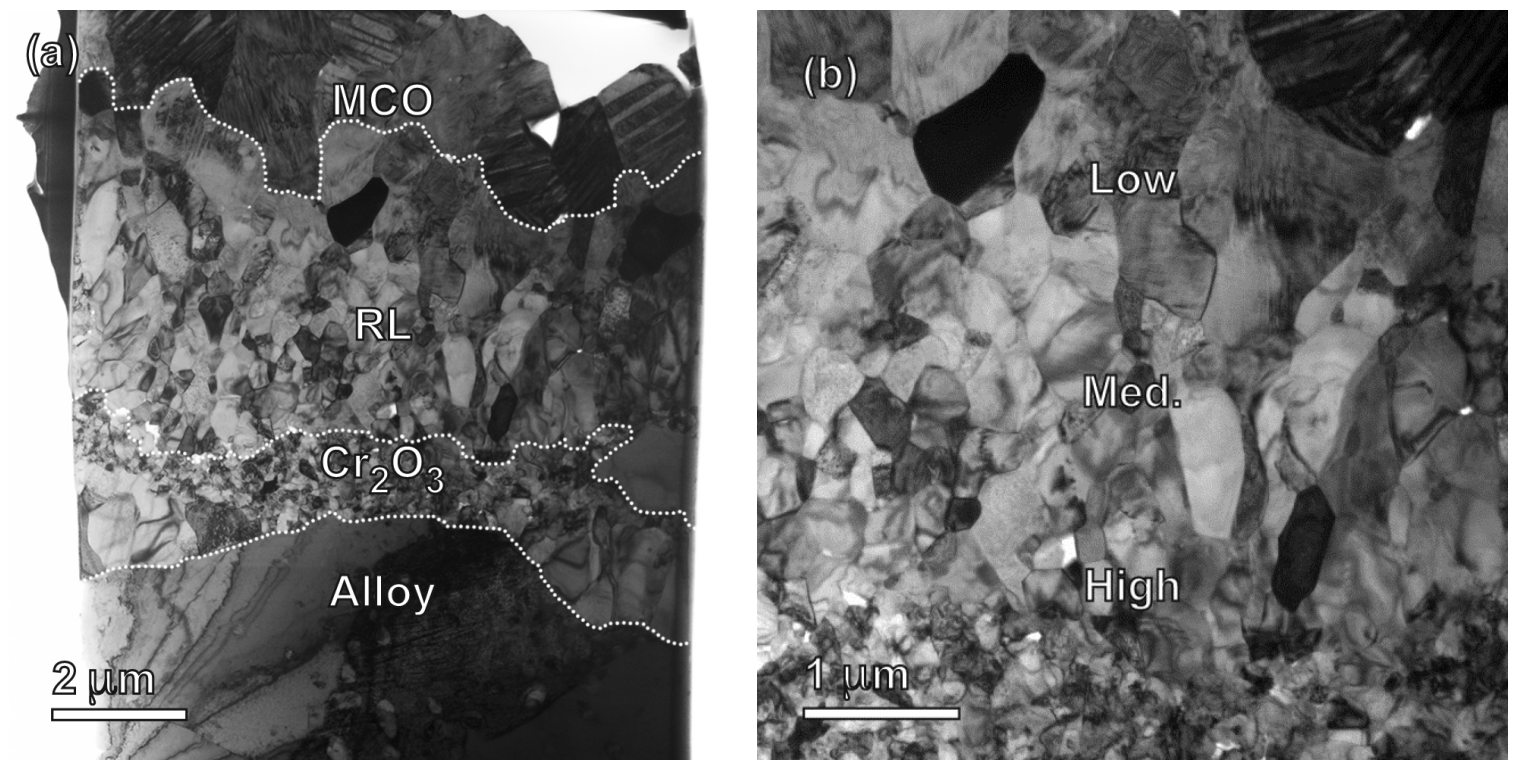

Figure 2: Bright field TEM images from a FIB-cut cross-section through an MCO-coated Crofer 22 APU sample that had been oxidized for $1000 \mathrm{~h}$ in air.
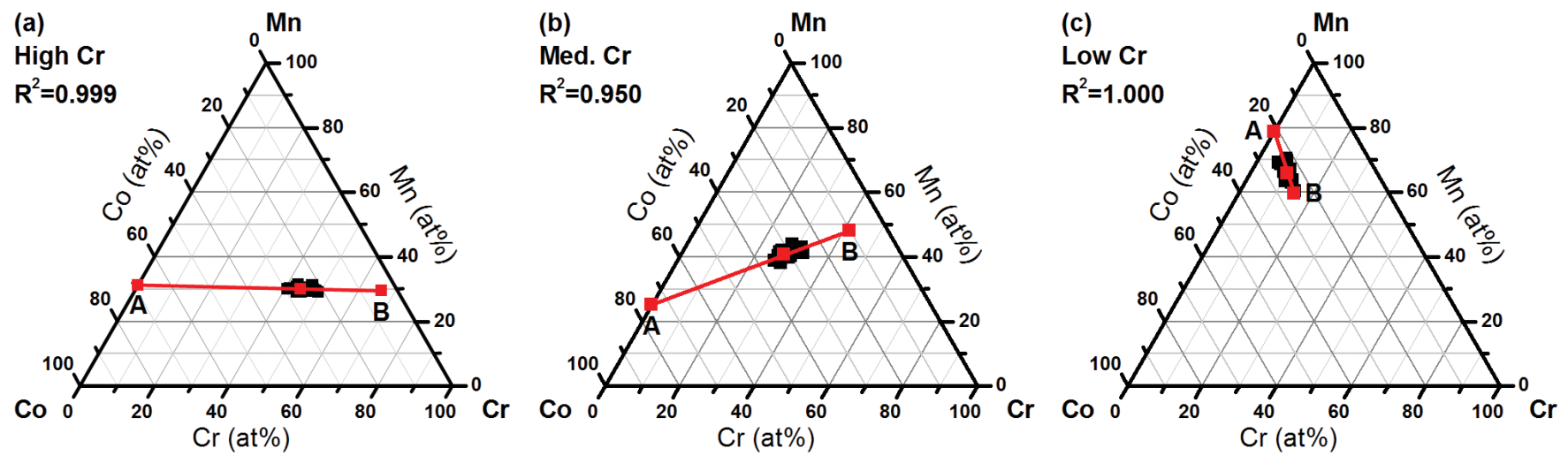

Figure 3: OTL plots of ALCHEMI data obtained from grains in regions of the RL shown in Figure 2(b). 